\title{
Cranial base pathology in pediatric osteogenesis imperfecta patients treated with bisphosphonates
}

\author{
Heidi Arponen, DDS, PhD, ${ }^{1}$ llkka Vuorimies, MD, ${ }^{2}$ Jari Haukka, $\mathrm{PhD},{ }^{3}$ Helena Valta, MD, PhD, ${ }^{2}$ \\ Janna Waltimo-Sirén, DDS, PhD, ${ }^{1}$ and Outi Mäkitie, MD, PhD²,4,5 \\ 'Department of Orthodontics, Institute of Dentistry, University of Helsinki; ${ }^{2}$ Children's Hospital, Helsinki University Central \\ Hospital and University of Helsinki; ${ }^{3}$ Hjelt Institute, University of Helsinki; ${ }^{4}$ Folkhälsan Research Center, Helsinki, Finland; and \\ ${ }^{5}$ Center for Molecular Medicine, Karolinska Institutet, and Department of Clinical Genetics, Karolinska University Hospital, \\ Stockholm, Sweden
}

OBJECT Cranial base pathology is a serious complication of osteogenesis imperfecta (OI). Our aim was to analyze whether bisphosphonate treatment, used to improve bone strength, could also prevent the development of craniocervical junction pathology (basilar impression, basilar invagination, or platybasia) in children with Ol.

METHODS In this single-center retrospective study the authors analyzed the skull base morphology from lateral skull radiographs and midsagittal MR images (total of 94 images), obtained between the ages of 0 and 25 years in 39 bisphosphonate-treated OI patients. The results were compared with age-matched normative values and with findings in $70 \mathrm{OI}$ patients who were not treated with bisphosphonates. In addition to cross-sectional data, longitudinal data were available from 22 patients with an average follow-up period of 7.6 years. The patients, who had OI types I, III, IV, VI, and VII, had been treated with zoledronic acid, pamidronate, or risedronate for 3.2 years on average.

RESULTS Altogether $33 \%$ of the 39 bisphosphonate-treated patients had at least 1 cranial base anomaly, platybasia being the most prevalent diagnosis (28\%). Logistic regression analysis suggested a higher risk of basilar impression or invagination in patients with severe OI (OR 22.04) and/or older age at initiation of bisphosphonate treatment (OR 1.45), whereas a decreased risk was associated with longer duration of treatment (OR 0.28$)$. No significant associations between age, height, or cumulative bisphosphonate dose and the risk for cranial base anomaly were detected. In longitudinal evaluation, Kaplan-Meier curves suggested delayed development of cranial base pathology in patients treated with bisphosphonates but the differences from the untreated group were not statistically significant.

CONCLUSIONS These findings indicate that cranial base pathology may develop despite bisphosphonate treatment. Early initiation of bisphosphonate treatment may delay development of craniocervical junction pathology. Careful followup of cranial base morphology is warranted, particularly in patients with severe OI.

http://thejns.org/doi/abs/10.3171/2014.11.PEDS14113

KEY WORDS osteogenesis imperfecta; bisphosphonates; craniocervical junction; basilar invagination; basilar impression; congenital

$\mathrm{O}$ STEOGENESIS imperfecta (OI) is a heterogeneous group of rare inherited connective tissue disorders characterized by Type I collagen abnormalities. The disorder affects bone, resulting in an osteoporotic phenotype, and other collagen-rich tissues, such as liga- ments. The annual worldwide incidence of OI has been reported to be 1 in 10,000 to 20,000 births. ${ }^{1,16,38}$ Approximately $90 \%$ of cases are caused by dominant mutations in the genes coding for Type I collagen alpha chains (COL1A1 and COL1A2), ${ }^{29}$ and the majority fit into the

ABBREVIATIONS $\mathrm{CM}-\mathrm{I}=$ Chiari malformation Type I; OI = osteogenesis imperfecta .

SUBMITTED March 5, 2014. ACCEPTED November 20, 2014

INCLUDE WHEN CITING Published online January 9, 2015; DOI: 10.3171/2014.11.PEDS14113.

DISCLOSURE This study was supported by grants (to H.A.) from the Finnish Association of Women Dentists, (to I.V. and O.M.) from Sigrid Juselius Foundation, (to O.M.) from the Finnish Foundation for Pediatric Research, the Academy of Finland, the Folkhälsan Research Foundation, the Helsinki University Hospital Research Funds, and the Swedish Research Council. 
widely used classification by Sillence and colleagues that divides OI into 4 types based on clinical and radiological findings and mode of inheritance. ${ }^{36} \mathrm{~A}$ fifth distinct autosomal dominant type of OI was added to the classification by Glorieux and coworkers. ${ }^{17}$ Autosomal recessive OI types, labeled in the literature as types VI-XV, are rare and range from moderate to lethal in clinical severity. ${ }^{6,14,23,33}$ These usually arise from mutations that generate deficiencies of proteins involved in posttranslational modification, folding, or secretion of Type I collagen..$^{14,25}$ Clinical classification of OI can be challenging due to overlapping characteristics (Table 1), but phenotypically the various forms can be divided into mild, moderate, severe, or lethal based on clinical severity of the disorder.

Craniocervical pathology is one of the most serious complications of OI, and it predominantly affects patients with severe OI types..$^{10,22}$ It may be asymptomatic or may lead to compression of the brainstem and/or related neurovascular structures, resulting in a variety of subsequent neurological complications and symptoms. Chiari malformation is a possible comorbidity. ${ }^{19,27}$ Severe pathology can lead to perinatal death, whereas milder forms restrict life and cause moderate reduction of life span. ${ }^{29}$ Pathology of the craniocervical junction and cranial base can be divided into 1) basilar impression, characterized by relative lowering of the skull base with endocranial introflection of the posterior edge of the foramen magnum; 2) basilar invagination, where the uppermost cervical structures protrude into the cranium; and 3) platybasia or flattening of the skull base. These 3 entities are separate, although they frequently coincide. ${ }^{22}$ Neurosurgery with posterior occipitocervical fusion may be necessary to correct the effects of severe basilar invagination or impression..$^{21}$ The surgical treatment planning relies on radiographs and MR and CT images obtained with flexion and extension of the head. ${ }^{24}$ Conventional lateral skull radiography is usually the first-line imaging modality in screening patients for further evaluation with MRI or CT. ${ }^{21}$

The most significant progress in the treatment of OI has been the implementation of bisphosphonate therapy (since 1988) to increase bone mass and prevent fractures by reducing bone resorption. Reported benefits include increased bone mineral density and cortical bone thickness; reduction in fracture rate, deformity of long bones, and bone pain; normalization of vertebral morphology; and increased mobility., $5,32,40,41$ The aim of the present study was to analyze whether bisphosphonates also affect the morphology of the craniocervical junction and cra- nial base. This possible effect has previously been largely unexplored.

\section{Methods}

\section{Patient Cohort}

This retrospective cohort study was carried out at the Children's Hospital, Helsinki University Central Hospital, Finland. The study was approved by the hospital's research ethics committee. The study cohort consisted of OI patients who were at the time of the study or had previously been under follow-up at the Metabolic Bone Clinic, Children's Hospital. The inclusion criteria were 1) diagnosis of OI, 2) treatment with bisphosphonates during growth, and 3) availability of radiographic evaluation of the cranial base during bisphosphonate treatment. The study inclusion cut-off age was set at 25 years, up to which age vertebral body growth has been reported to normally occur. ${ }^{18}$

Altogether 39 patients (22 males and 17 females) fulfilled the inclusion criteria. They represented OI types I, III, IV, VI (1 patient), and VII (1 patient) based on clinical and radiological features and available genetic data. Their patient files were reviewed to obtain data on the frequency of fractures, neurological status, and symptoms. Possible neurological symptoms of brainstem pathology, such as cervical myelopathy, bulbar symptoms, and headache or neck pain, had been looked for in clinical examinations. The patients' height measurements were converted to ageand sex-specific $\mathrm{z}$ scores according to Finnish references. ${ }^{37}$

Radiographs and MRI studies were obtained on clinical indications for diagnosis, follow-up, and treatment planning and were reviewed retrospectively for this study. The age of the patients ranged from 0 to 24.8 years at the time of imaging. Longitudinal radiographic/MRI data were available for 22 patients (56\%). For 20 of these patients, images had been obtained both before and after the onset of bisphosphonate treatment. Changes in the angulation of the cranial base and in the dimensions of the craniocervical junction were assessed for a mean observation period of 7.6 years (range 1.3-19.0 years).

To determine whether bisphosphonate treatment influenced the development of cranial base pathology, we used a historical comparison group of 70 patients (OI types I, III, and IV), aged between 0 and 39 years, who were not treated with bisphosphonates. The comparison group included longitudinal data on 23 patients aged between 0 and 23 years. ${ }^{4}$

TABLE 1. Classification of the autosomal dominant forms of OI into 5 clinically and radiologically distinct types I-V*

\begin{tabular}{ccll}
\hline Type & Inheritance & \multicolumn{1}{c}{ Gene Defect } & \multicolumn{1}{c}{ Phenotype } \\
\hline I & AD & COL1A1 or COL1A2 & Mild, nondeforming \\
\hline II & AD & COL1A1 or COL1A2 & Lethal \\
\hline III & AD & COL1A1 or COL1A2 & Severe, rhizomelic dwarfism, progressive bone deformity \\
\hline IV & AD & COL1A1 or COL1A2 & Moderate, slightly shortened height \\
\hline V & AD & IFITM5 & $\begin{array}{l}\text { Moderate to severe deformity, hyperplastic callus formation, mineralized } \\
\text { forearm intraosseous membrane }\end{array}$ \\
\hline
\end{tabular}

$A D=$ autosomal dominant mode of inheritance.

* Autosomal recessive OI types are distinguishable by the gene defect and have a phenotype ranging from moderate to lethal. 


\section{Bisphosphonate Treatment}

The decision to treat patients with bisphosphonates had been made individually based on the patient's clinical features and symptoms. According to local guidelines, the patients were eligible for treatment if they had 1) a history of frequent fractures, 2) vertebral compression fractures, or 3) chronic disabling bone pain and/or 4) their vulnerability to fractures was estimated as being high. Prior to treatment, the patients and their parents were informed of the potential common side effects, such as hypocalcemia and fever, and of rare complications.

The patients were treated according to an individual treatment plan. They were assessed clinically, and serum and urine samples for bone turnover markers were obtained at baseline and during treatment. The patients were treated with zoledronic acid, pamidronate, or risedronate. Zoledronic acid infusions (Zometa, Novartis Pharma, Switzerland) were administered intravenously $0.025-$ $0.05 \mathrm{mg} / \mathrm{kg}$ up to $2.0-4.0 \mathrm{mg}$ once every 3-6 months. Pamidronate infusions (Aredia, Novartis Pharma, Switzerland; and Pamifos, Medac, Germany) were administered intravenously $0.5-1.0 \mathrm{mg} / \mathrm{kg} /$ day up to $60 \mathrm{mg}$ for 3 days every 2-4 months. Orally administered risedronate (Optinate, Warner Chilcott, Germany) was given daily; patients weighing $10-30 \mathrm{~kg}$ received $2.5 \mathrm{mg}$, and patients weighing more than $30 \mathrm{~kg}$ received $5 \mathrm{mg}$ daily. Bisphosphonate treatment was usually continued for 2-3 years and repeated, if necessary, after a treatment-free period. In addition, according to local practice, all patients with OI received daily vitamin D3 and calcium supplements according to their weight, if hypercalciuria was not present, during the treatment.

Cumulative bisphosphonate dose was calculated as the total dose received (in milligrams) per weight (in kilograms) times the relative potency of the chosen medication. The relative potency of bisphosphonates to inhibit bone resorption was applied as presented by Shaw and Bishop, assuming etidronate as having a potency of 1 , pamidronate a potency of 100 , risedronate a potency of 2000 , and zoledronic acid a potency of 10,000. The bioavailability of risedronate is $0.63 \% .34$

The use of bisphosphonates in the treatment of pediatric OI patients was started in Finland in the year 2000, first in patients with severe OI and later also in those with milder forms. Therefore, there was a wide age range at the treatment onset in our cohort. The mean age of the patients was 7.9 years at the start of the treatment, and the mean duration of treatment was 3.2 years.

\section{Cephalometric Analysis}

The study was based on 94 lateral images of the skull (2 midsagittal MR images and 92 radiographs). The images were analyzed using a specially programmed algorithm in Viewbox software (version 3, dHal). Two examiners identified together on all the images 7 cephalometric landmark points based on which 3 cranial base measures were calculated (Fig. 1). The reliability and applicability of the method has been previously reported together with normal values for healthy ethnic Finns. ${ }^{2-4}$

We used the following definitions and diagnostic criteria. Basilar invagination was diagnosed when the McRae

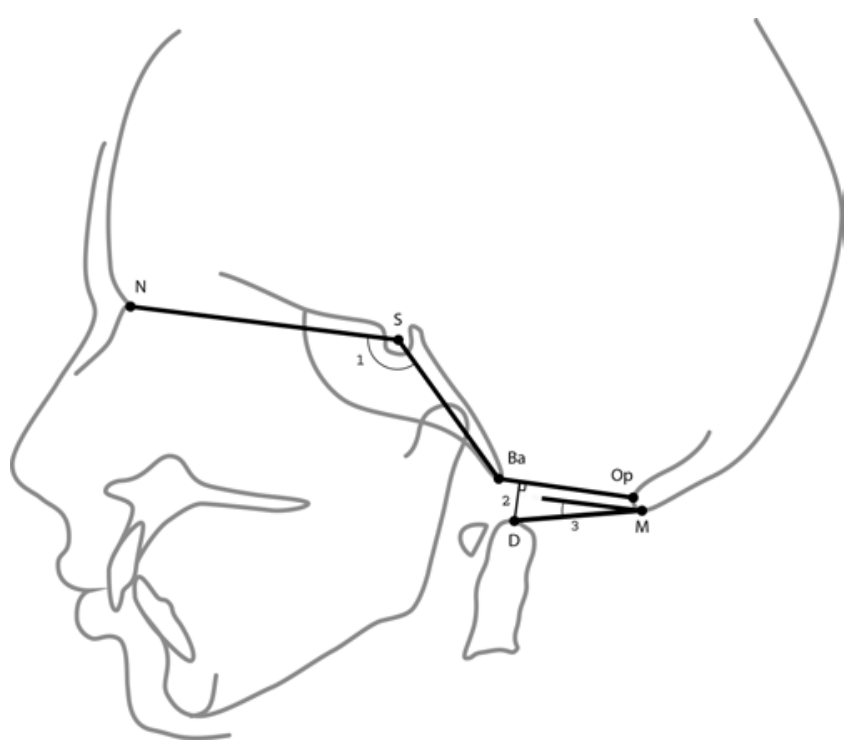

FIG. 1. Cranial base reference lines, angles, and measurements. The illustration depicts normal anatomy. 1) Anterior cranial base angle: nasion-sella-basion angle (N-S-Ba). 2) McRae's measure: perpendicular distance of the tip of the odontoid process (D) to the foramen magnum line running from basion to opisthion (Ba-Op), normally negative. 3) D-M angle: angle between a line running through the lowest point $(\mathrm{M})$ of the occipital curve parallel to the nasion-sella line and a line drawn from $M$ to $D$, normally negative.

measure was at or above 0 . Basilar impression was diagnosed when the D-M angle exceeded 2.5 SD from the average age-specific norms. Platybasia was diagnosed when the anterior cranial base angle was more than 2.5 SD above the average age-specific norms. Patients who fulfilled at least one of these diagnoses were considered to have a cranial base anomaly.

\section{Statistical Analysis}

Generalized linear mixed model (Douglas Bates, Martin Maechler, and Ben Bolker, lme4: Linear mixed-effects models using S4 classes, 2011, http://cran.r-project. org/package=lme4.) was used to analyze the association between the cranial base anomalies and patient characteristics. Potential predictor variables were bisphosphonate treatment history (age at the onset of medication, duration of treatment, and cumulative dose), age, sex, and height $\mathrm{z}$ score, as well as OI type (mild, moderate, or severe). Cranial base anomaly was a dichotomous (yes/no) variable. Sex, OI type, and medication status were used as fixed effects and patient-specific intercept as random effect. Statistical calculations were done using the $\mathrm{R}$ language (version 2.13.0, R Development Core Team, R: A Language and Environment for Statistical Computing, Vienna, Austria, 2008). Differences between groups in the Kaplan-Meier survival estimator were tested using a logrank test in SPSS. A Pearson correlation coefficient was computed to assess the relationship between the occurrence of cranial base anomalies and fracture frequency in SPSS (version 18, SPSS Inc.). 
TABLE 2. Description of the OI patient cohort

\begin{tabular}{|c|c|c|c|c|}
\hline Characteristic & Mild (Type I) & Moderate (Types IV \& VI) & Severe (Types III \& VII) & Total \\
\hline No. of patients & 20 & 10 & 9 & 39 \\
\hline Height z score (mean) & -0.6 & -3.3 & -5.2 & -2.6 \\
\hline Age range (yrs) & $0-18.1$ & $1.3-24.8$ & $0-19.3$ & $0-24.8$ \\
\hline \multicolumn{5}{|l|}{$\begin{array}{l}\text { Age at bisphosphonate treatment onset } \\
\text { (yrs) }\end{array}$} \\
\hline Mean & 7.5 & 10.4 & 4.8 & 7.9 \\
\hline Range & $1.2-13.2$ & $2.4-24.3$ & $0.1-18.3$ & $0.1-24.3$ \\
\hline \multicolumn{5}{|l|}{ Duration of treatment (yrs) } \\
\hline Mean & 3.5 & 2.9 & 2.8 & 3.2 \\
\hline Range & $0.1-8.3$ & $0.2-10.9$ & $0.9-5.5$ & $0.1-10.9$ \\
\hline \multicolumn{5}{|l|}{$\begin{array}{l}\text { Duration of follow-up after onset of treat- } \\
\text { ment (yrs) }\end{array}$} \\
\hline Mean & 3.6 & 4.3 & 3.3 & 3.7 \\
\hline Range & $0.1-8.3$ & $0.2-10.9$ & $0.9-5.2$ & $0.1-10.9$ \\
\hline Cumulative bisphosphonate dose (mean)* & 1639 & 2425 & 2543 & 2080 \\
\hline
\end{tabular}

* Cumulative bisphosphonate dose was calculated as (total dose received [mg]/weight [kg]) times the relative potency of the medication.

\section{Results}

\section{Cohort Characteristics}

Cohort characteristics are summarized in Table 2. Twenty patients had mild OI, in 10 patients OI was classified as moderate, and in 9 patients as severe. The mean age at bisphosphonate treatment onset was 7.9 years in the whole cohort, and the mean duration of treatment was 3.2 years.

\section{Cross-Sectional Analysis}

Cranial base anomalies were present in all studied OI types and were more frequent in the severe types. Of the patients with mild OI, $25 \%$ exhibited a cranial base anomaly. Of those with moderate OI, 70\% had an anomaly, and of patients with severe OI 78\%. Altogether $13(33 \%)$ of the 39 patients had at least 1 cranial base anomaly at some point (Table 3). Platybasia was the most prevalent diagnosis (28\%). Of those with platybasia, $33 \%$ also had another cranial base anomaly.

Logistic regression analysis suggested that a higher risk for basilar impression or basilar invagination correlated with the severity of OI (Type III, OR $22.04,95 \%$ CI
$1.26-386.28, \mathrm{p}=0.040$ ), older age at the onset of medication (OR 1.45, 95\% CI 1.01-2.09, $\mathrm{p}=0.044)$, and short duration of treatment (length of treatment duration, OR $0.28,95 \%$ CI $0.087-0.91, p=0.034)$. No significant associations between age, sex, height of the patient, or cumulative bisphosphonate dose and the risk of having a cranial base anomaly were detected.

\section{Longitudinal Analysis}

Eight patients exhibited a cranial base anomaly already before the initiation of bisphosphonate treatment. In 4 of them, the pathology persisted. Basilar impression and invagination persisted in the follow-up, whereas platybasia was later no longer detected in 4 patients previously diagnosed with it. Basilar impression or invagination was not diagnosed in patients under the age of 3 even prior to the start of the treatment. Platybasia, however, was present from birth, suggesting antenatal development.

After the onset of bisphosphonate treatment, 5 patients (23\%) previously not displaying cranial base pathology, developed an anomaly at ages ranging from 1 to 18 years; 4 developed platybasia, and 1 developed basilar invagination. In addition, 1 boy with moderate OI (Type IV) acquired

TABLE 3. Prevalence of craniocervical anomalies in the present study and in previous studies of Finnish Ol patients with similar diagnostic criteria

\begin{tabular}{|c|c|c|c|c|c|c|}
\hline \multirow[b]{2}{*}{ Authors \& Year } & \multirow[b]{2}{*}{$\begin{array}{c}\text { No. of } \\
\text { Patients }\end{array}$} & \multirow[b]{2}{*}{$\begin{array}{l}\text { Age Range } \\
\text { (yrs) }\end{array}$} & \multirow[b]{2}{*}{$\begin{array}{l}\text { Distribution of OI Types } \\
\text { (mild/moderate/severe) }\end{array}$} & \multicolumn{3}{|c|}{ Prevalence of Cranial Base Anomalies } \\
\hline & & & & $\begin{array}{c}\text { Basilar } \\
\text { Impression }\end{array}$ & $\begin{array}{c}\text { Basilar } \\
\text { Invagination }\end{array}$ & Platybasia \\
\hline Present study & 39 & $0-25$ & $20 / 10 / 9$ & $7(18 \%)$ & $6(15 \%)$ & $11(28 \%)$ \\
\hline Arponen et al., 2012* & 70 & $0-39$ & $46 / 10 / 14$ & $13 \%$ & $13 \%$ & $23 \%$ \\
\hline Kovero et al., $2006 \dagger$ & 54 & $16-69$ & $29 / 19 / 5$ & $17 \%$ & $22 \%$ & $11 \%$ \\
\hline
\end{tabular}



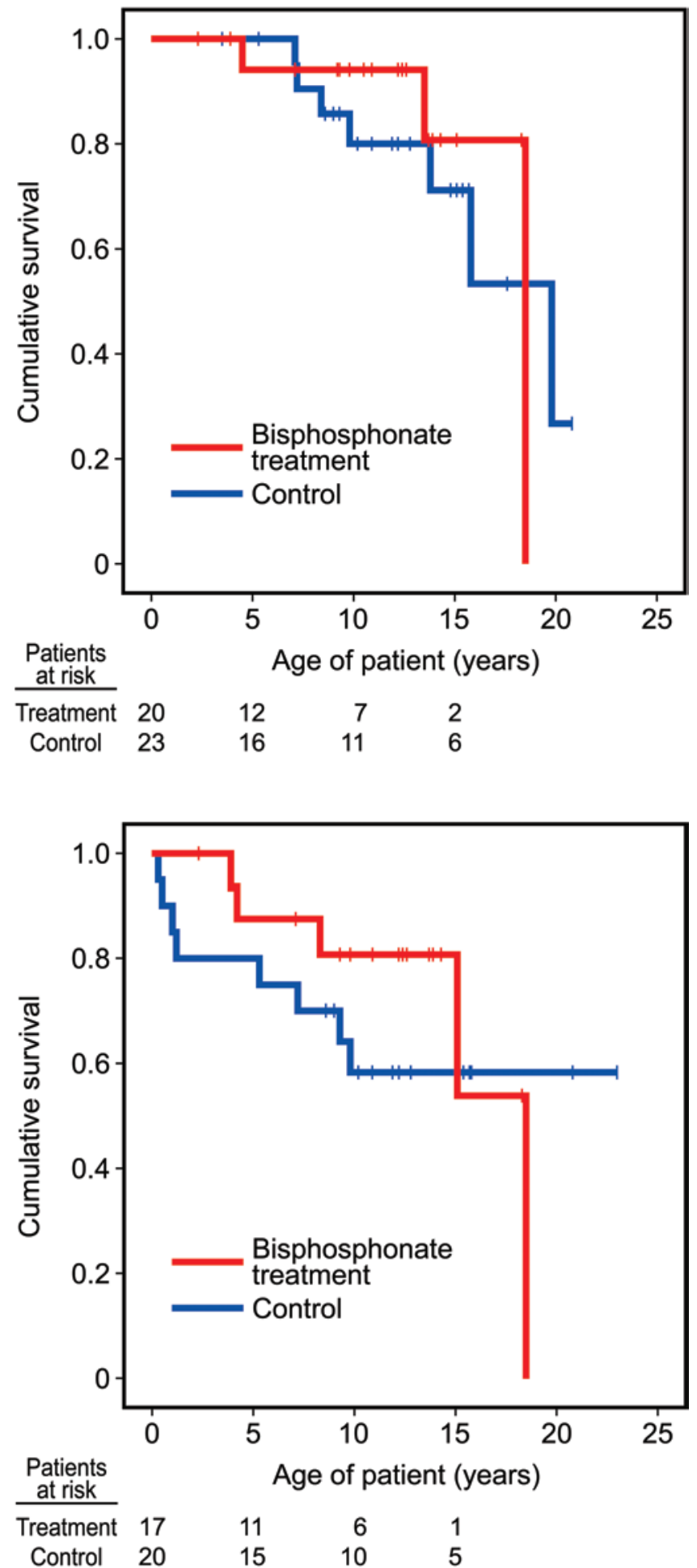

FIG. 2. Kaplan-Meier curves for the age to basilar impression (upper) and platybasia (lower). The red lines indicate findings in the bisphosphonate-treated study group, and the blue lines indicate findings in a previously described control group of Ol patients not treated with bisphosphonates. ${ }^{4}$ Numbers of patients at risk at each time point are given below the figures. both basilar impression and platybasia 2 years after the onset of treatment at the age of 13.5 years, adding to existing basilar invagination. A boy with severe OI (Type III) acquired both basilar impression and basilar invagination 1.2 years after the onset of treatment at the age of 4.5 years.

Figure 2 displays Kaplan-Meier curves from longitudinal follow-up of the study group and the comparison group of patients not treated with bisphosphonates. There was a trend toward delayed development of cranial base pathology in the treated patients. However, no statistically significant difference was detected in the time to occurrence of pathology between the 2 groups (basilar impression, $\log$ rank $=0.205$ on $1 \mathrm{df}, \mathrm{p}=0.651$; platybasia, $\log$ rank $=0.326$ on $1 \mathrm{df}, \mathrm{p}=0.568$ ). In 8 patients, bisphosphonate treatment was started under the age of 3 years. None of these patients developed later basilar impression or invagination during follow-up ranging from 1 to 8 years. Figure 3 illustrates the cranial base status in the patients with early and late onset of treatment after a minimum of 2-year treatment duration.

\section{Neurological Symptoms and Fracture Rate}

Most of the patients (74\%) were household or community walkers according to the criteria of $\mathrm{Bleck}^{8}$ and Engelbert et al. ${ }^{12}$ Ten patients with the most severe OI were, however, nonwalkers. All but one of them displayed a cranial base anomaly, further supporting the association between cranial anomalies and the severity of OI. However, statistically the association between cranial base anomalies and level of ambulation was weak (phi = $-0.40, \mathrm{p}=0.013)$.

Of the 13 patients with cranial base anomalies, only 3 experienced related symptoms. An 18-year-old male with moderate (Type IV) OI and all 3 cranial base anomalies suffered from recurring headache. His twin sister, who also had moderate OI (Type IV) and all 3 cranial base anomalies, was referred to a pediatric surgeon for treatment planning following diagnosis of Chiari malformation Type I (CM-I). Her main symptom was recurring

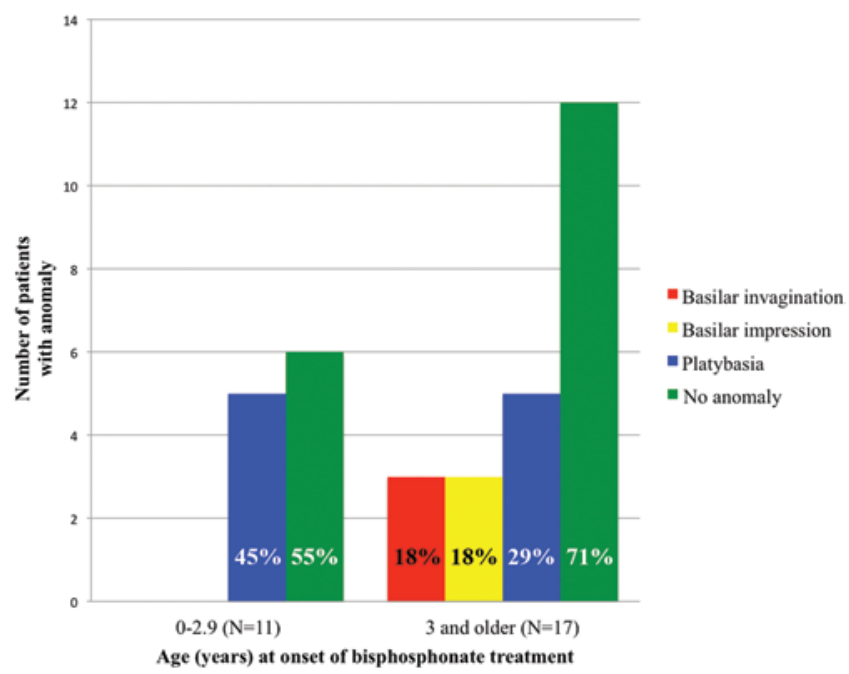

FIG. 3. Cranial base status of OI patients after a minimum of 2 years of bisphosphonate treatment. 
headache. A male patient with severe OI (Type III) and all 3 cranial base anomalies underwent surgical treatment of the pathology during the follow-up period. Surgical decompression and posterior stabilization was performed at the age of 8 years due to CM-I with a sole clinical symptom of muscle weakness in lower limbs first detected a year prior to surgery. Chiari malformation was diagnosed on the MRI. An MRI study was performed following a radiographic finding suggestive of pathology. Polysomnography was employed in 1 case involving a patient with severe OI and no radiologically detected craniocervical anomalies. She was found to have an only slightly decreased tidal volume associated with her small truncal height (height $\mathrm{z}$ score -7). The youngest patients were not expected to be able to report all possible symptoms. A 3.8-year-old girl with severe OI only moved on the floor by pulling herself on her back. As noted in physiotherapy, she was reluctant to flex or extend her head, which could be a sign of discomfort. Her radiographic analysis revealed measures just below the limit of pathology.

Data on radiologically diagnosed vertebral and peripheral fractures were available for 27 patients, with an average yearly fracture frequency of 0.80 before bisphosphonate treatment and 0.72 after initiation of treatment. The difference was statistically insignificant, with age and level of activity as confounders. The frequency of fractures after initiation of bisphosphonate treatment and the likelihood of developing or retaining a cranial base anomaly did not correlate $(\mathrm{r}[27]=0.21, \mathrm{p}=0.296)$.

\section{Discussion}

The ligamentous and bony structures of the craniocervical junction allow movements of the head and provide structural support. Craniocervical instability may develop in skeletal dysplasias, such as OI, where craniocervical junction anomalies have been observed in mild, moderate, and severe types of OI, but not in the perinatally lethal type. ${ }^{31}$ We undertook this study to explore whether bisphosphonate treatment, used to improve bone strength, could also avert the possible serious complication of craniocervical junction pathology in children with OI.

In this cross-sectional and longitudinal study, we found a prevalence of cranial base anomalies in 39 bisphosphonate-treated patients that was similar to the prevalence found in our previous study on growing OI patients not treated with bisphosphonates, with the same threshold limits and comparable clinical and ethnic background of the patients. ${ }^{4}$ As in untreated patients, notable individual variation was observed in the treated patients with respect to the course of the anomalies with growth. In some patients the anomaly progressed, whereas in some an improvement was seen. When compared with the historical group of OI patients with comparable severity and no exposure to bisphosphonates, a trend toward delayed development of cranial base pathology was observed (Fig. 2). However, the differences between the groups were not statistically significant.

The pathogenesis of craniocervical pathology in OI is believed to involve a combinative effect of bone fragility, malleability, and excessive ligament laxity. In an upright position, particularly, the weight of the brain compresses the cranial base, causing microfractures. Simultaneously, the cervical spine migrates upwards relative to the cranium. ${ }^{15,31,35} \mathrm{~A}$ delay in adoption of an upright position has been documented in children with OI. The delay is most evident in the severe forms of the disorder. The mean age at which standing occurs has been reported to be 11 months in Type I, 16 months in Type IV, and 40 months in Type III OI. ${ }^{39}$ In our cohort, which represented a wide age range, the similar fracture frequency rate before and after the onset of bisphosphonate treatment might reflect a higher activity level following treatment, which can in turn result in more traumatic fractures, as noted for instance by Ward and coworkers..$^{41}$ Numerous additional factors, such as presence of long-bone deformities, influence the fracture rate. No cases of osteonecrosis of the jaws, as an adverse affect of the bisphosphonate treatment, occurred in our study cohort.

Our findings are consistent with previous ones in that basilar impression and invagination are detected from the age of 2 years onwards, whereas platybasia may be present from birth. ${ }^{4}$ The significance of platybasia is disputed. ${ }^{26}$ In previous studies, it has been associated with basilar impression and invagination., ${ }^{9,22}$ Patients with a larger anterior cranial base angle display a more horizontally oriented clivus and subsequently can be expected to have an elevated curvature of the brainstem, which causes compression of the ventral brainstem. Platybasia has been suggested to predispose to the development of Chiari malformation by leading to overcrowding of the posterior fossa and consequently to tonsillar herniation through the foramen magnum..$^{13} \mathrm{~A}$ spontaneous recovery from platybasia, as seen in this study, can be explained by the naturally occurring steepening of the anterior cranial base angle with growth. ${ }^{20}$ As further support, platybasia has been found to be less prevalent in older OI patients not treated with bisphosphonates (Table 3). ${ }^{22}$

The strength of this study is that the radiographs were obtained in an upright position. Relationships between the craniocervical junction structures have been shown to differ in supine and upright positions in patients with Ehlers-Danlos syndrome, ${ }^{28}$ with features overlapping with OI in terms of ligament laxity. Thus, it can be speculated that in OI as well, the odontoid process is brought closer to the clivus in the upright position, which would affect both McRae and D-M measures by increasing the values and decreasing the number of false-negative results. The weaknesses of this study are the limited cohort size due to the rarity of OI, the wide clinical heterogeneity of OI as a disorder, variable treatment protocols and duration, and the use of mainly 2D images. Power analysis displays the weakness of the statistical analysis, for an odds ratio of 0.20 the power was $23 \%$.

Our findings corroborate the previous recommendation for radiological screening of all pediatric patients with OI before school age, after which individually adjusted follow-up is warranted in patients with abnormal radiological findings and/or neurological symptoms. ${ }^{4}$

\section{Conclusions}

Our study shows that cranial base anomalies may 
develop despite bisphosphonate treatment. Treatment started in infancy may delay the development of craniocervical junction pathology. The preventive effect of bisphosphonate treatment remains unclear. The ligaments and vertebral instability are likely to play a major role in the development of craniocervical pathology after a child attains an upright posture, and bisphosphonate therapy may not have a significant impact on these factors. Our finding that cranial base anomalies may develop despite bisphosphonate treatment is consistent with previous studies. ${ }^{4,11}$ Further studies in larger patient cohorts with extended follow-up are needed to confirm our findings; the use of MRI in longitudinal follow-up would give more detailed data on the progression of cranial base pathology. The overall effects of bisphosphonates on the skeleton are growth dependent, and thus early treatment initiation is recommended..$^{30}$ Our results give further support to this recommendation.

\section{References}

1. Andersen PE Jr, Hauge M: Osteogenesis imperfecta: a genetic, radiological, and epidemiological study. Clin Genet 36:250-255, 1989

2. Arponen H, Elf H, Evälahti M, Waltimo-Sirén J: Reliability of cranial base measurements on lateral skull radiographs. Orthod Craniofac Res 11:201-210, 2008

3. Arponen H, Evälahti M, Waltimo-Sirén J: Dimensions of the craniocervical junction in longitudinal analysis of normal growth. Childs Nerv Syst 26:763-769, 2010

4. Arponen H, Mäkitie O, Haukka J, Ranta H, Ekholm M, Mäyränpää MK, et al: Prevalence and natural course of craniocervical junction anomalies during growth in patients with osteogenesis imperfecta. J Bone Miner Res 27:11421149,2012

5. Aström E, Söderhäll S: Beneficial effect of bisphosphonate during five years of treatment of severe osteogenesis imperfecta. Acta Paediatr 87:64-68, 1998

6. Bishop N: Characterising and treating osteogenesis imperfecta. Early Hum Dev 86:743-746, 2010

7. Bishop N, Adami S, Ahmed SF, Antón J, Arundel P, Burren $\mathrm{CP}$, et al: Risedronate in children with osteogenesis imperfecta: a randomised, double-blind, placebo-controlled trial. Lancet 382:1424-1432, 2013

8. Bleck EE: Nonoperative treatment of osteogenesis imperfecta: orthotic and mobility management. Clin Orthop Relat Res (159):111-122, 1981

9. Botelho RV, Ferreira ED: Angular craniometry in craniocervical junction malformation. Neurosurg Rev 36:603-610, 2013

10. Charnas LR, Marini JC: Communicating hydrocephalus, basilar invagination, and other neurologic features in osteogenesis imperfecta. Neurology 43:2603-2608, 1993

11. Cheung MS, Arponen H, Roughley P, Azouz ME, Glorieux FH, Waltimo-Sirén J, et al: Cranial base abnormalities in osteogenesis imperfecta: phenotypic and genotypic determinants. J Bone Miner Res 26:405-413, 2011

12. Engelbert RH, Uiterwaal CS, Gulmans VA, Pruijs H, Helders PJ: Osteogenesis imperfecta in childhood: prognosis for walking. J Pediatr 137:397-402, 2000

13. Fernandes YB, Ramina R, Campos-Herrera CR, Borges G: Evolutionary hypothesis for Chiari type I malformation. Med Hypotheses 81:715-719, 2013

14. Forlino A, Cabral WA, Barnes AM, Marini JC: New perspectives on osteogenesis imperfecta. Nat Rev Endocrinol 7:540-557, 2011
15. Frank E, Berger T, Tew JM Jr: Basilar impression and platybasia in osteogenesis imperfecta tarda. Surg Neurol 17:116119, 1982

16. Glorieux FH: Osteogenesis imperfecta. Best Pract Res Clin Rheumatol 22:85-100, 2008

17. Glorieux FH, Rauch F, Plotkin H, Ward L, Travers R, Roughley P, et al: Type $\mathrm{V}$ osteogenesis imperfecta: a new form of brittle bone disease. J Bone Miner Res 15:1650-1658, 2000

18. Harrison GA, Weiner JS, Tanner JM, Barnicot NA: Human Biology, ed 2. Oxford, UK: Oxford University Press, 1977, p 357

19. Hayes M, Parker G, Ell J, Sillence D: Basilar impression complicating osteogenesis imperfecta type IV: the clinical and neuroradiological findings in four cases. J Neurol Neurosurg Psychiatry 66:357-364, 1999

20. Kerr WJ, Hirst D: Craniofacial characteristics of subjects with normal and postnormal occlusions-a longitudinal study. Am J Orthod Dentofacial Orthop 92:207-212, 1987

21. Khandanpour N, Connolly DJ, Raghavan A, Griffiths PD, Hoggard N: Craniospinal abnormalities and neurologic complications of osteogenesis imperfecta: imaging overview. Radiographics 32:2101-2112, 2012

22. Kovero O, Pynnönen S, Kuurila-Svahn K, Kaitila I, WaltimoSirén J: Skull base abnormalities in osteogenesis imperfecta: a cephalometric evaluation of 54 patients and 108 control volunteers. J Neurosurg 105:361-370, 2006

23. Laine CM, Joeng KS, Campeau PM, Kiviranta R, Tarkkonen K, Grover M, et al: WNT1 mutations in early-onset osteoporosis and osteogenesis imperfecta. N Engl J Med 368:18091816,2013

24. Leone A, Costantini A, Visocchi M, Vestito A, Colelli P, Magarelli N, et al: The role of imaging in the pre- and postoperative evaluation of posterior occipito-cervical fusion. Radiol Med (Torino) 117:636-653, 2012

25. Marini JC, Blissett AR: New genes in bone development: what's new in osteogenesis imperfecta. J Clin Endocrinol Metab 98:3095-3103, 2013

26. McRae DL: Bony abnormalities in the region of the foramen magnum: correlation of the anatomic and neurologic findings. Acta Radiol 40:335-354, 1953

27. Menezes AH: Craniocervical developmental anatomy and its implications. Childs Nerv Syst 24:1109-1122, 2008

28. Milhorat TH, Bolognese PA, Nishikawa M, McDonnell NB, Francomano CA: Syndrome of occipitoatlantoaxial hypermobility, cranial settling, and Chiari malformation Type I in patients with hereditary disorders of connective tissue. J Neurosurg Spine 7:601-609, 2007

29. Rauch F, Glorieux FH: Osteogenesis imperfecta. Lancet 363:1377-1385, 2004

30. Rauch F, Travers R, Glorieux FH: Pamidronate in children with osteogenesis imperfecta: histomorphometric effects of long-term therapy. J Clin Endocrinol Metab 91:511-516, 2006

31. Sawin PD, Menezes AH: Basilar invagination in osteogenesis imperfecta and related osteochondrodysplasias: medical and surgical management. J Neurosurg 86:950-960, 1997

32. Semler O, Beccard R, Palmisano D, Demant A, Fricke O, Schoenau E, et al: Reshaping of vertebrae during treatment with neridronate or pamidronate in children with osteogenesis imperfecta. Horm Res Paediatr 76:321-327, 2011

33. Semler O, Garbes L, Keupp K, Swan D, Zimmermann K, Becker J, et al: A mutation in the 5'-UTR of IFITM5 creates an in-frame start codon and causes autosomal-dominant osteogenesis imperfecta type V with hyperplastic callus. Am J Hum Genet 91:349-357, 2012

34. Shaw NJ, Bishop NJ: Bisphosphonate treatment of bone disease. Arch Dis Child 90:494-499, 2005

35. Sillence DO: Craniocervical abnormalities in osteogenesis 
imperfecta: genetic and molecular correlation. Pediatr Radiol 24:427-430, 1994

36. Sillence DO, Senn A, Danks DM: Genetic heterogeneity in osteogenesis imperfecta. J Med Genet 16:101-116, 1979

37. Sorva R, Lankinen S, Tolppanen EM, Perheentupa J: Variation of growth in height and weight of children. II. After infancy. Acta Paediatr Scand 79:498-506, 1990

38. Stoll C, Dott B, Roth MP, Alembik Y: Birth prevalence rates of skeletal dysplasias. Clin Genet 35:88-92, 1989

39. Sutton R, Byers P, Hart T, Glorieux FH, Steiner RJ, Smith $\mathrm{P}$, et al: The OI Foundation Linked Clinical Research Centers longitudinal study, in: 11th International Conference on Osteogenesis Imperfecta. Hotel Palace/Dubrovnik/ Croatia/2nd - 5th October 2011 [Final Program \& Abstract Book]. Croatia: Croatian Paediatric Orthopaedic Society, 2011 (Abstract)

40. Vuorimies I, Toiviainen-Salo S, Hero M, Mäkitie O: Zoledronic acid treatment in children with osteogenesis imperfecta. Horm Res Paediatr 75:346-353, 2011

41. Ward LM, Rauch F, Whyte MP, D’Astous J, Gates PE, Grogan $\mathrm{D}$, et al: Alendronate for the treatment of pediatric osteo- genesis imperfecta: a randomized placebo-controlled study. J Clin Endocrinol Metab 96:355-364, 2011

\section{Author Contributions}

Conception and design: Arponen, Waltimo-Sirén, Mäkitie. Acquisition of data: Arponen, Vuorimies, Valta, Waltimo-Sirén, Mäkitie. Analysis and interpretation of data: Arponen, Vuorimies, Haukka, Waltimo-Sirén, Mäkitie. Drafting the article: Arponen. Critically revising the article: Arponen, Vuorimies, Valta, Waltimo-Sirén, Mäkitie. Reviewed submitted version of manuscript: all authors. Approved the final version of the manuscript on behalf of all authors: Arponen. Statistical analysis: Arponen, Haukka, Waltimo-Sirén. Study supervision: Waltimo-Sirén, Mäkitie.

\section{Correspondence}

Heidi Arponen, Department of Orthodontics, Institute of Dentistry, P.O. Box 41, University of Helsinki FI-00014, Finland. email: heidi.arponen@fimnet.fi. 